\title{
Comparative Studies between Chemical and Tribochemical Reactions of Some Metal Complexes Derived from $N$-(O-Hydoxyphenyl)- $N^{\prime}$-phenylthiourea (L)
}

\author{
Sawsan Mohamed Al-Ashqar \\ Department of Chemistry, Faculty of Applied Sciences, Umm Al-Qura University, Makkah, KSA \\ Email: d.sawsan94@hotmail.com
}

Received 22 January 2016; accepted 19 July 2016; published 22 July 2016

Copyright (C) 2016 by author and Scientific Research Publishing Inc.

This work is licensed under the Creative Commons Attribution International License (CC BY).

http://creativecommons.org/licenses/by/4.0/

(c) (i) Open Access

\section{Abstract}

The reactions of $\mathrm{N}$-(O-hydoxyphenyl)- $\mathrm{N}^{\prime}$-phenylthiourea (L) derived from with $\mathrm{Cu}^{+}, \mathrm{Cu}^{2+}, \mathrm{Co}^{2+}$ and $\mathrm{Co}^{3+}$ chloride and/or iodide afford new metal complexes. The isolated complexes were synthesized by two different techniques (chemical and tribochemical methods). Two complexes were synthesized by the direct chemical reactions of $N$ - $(O$-hydoxyphenyl)- $N$ '-phenylthiourea (L) with $\mathrm{MCl}_{2} \cdot \mathrm{XH}_{2} \mathrm{O}\left(\mathrm{M}=\mathrm{Co}^{2+}\right.$ and $\mathrm{Cu}^{2+} ; \mathrm{X}=6$ in case of $\mathrm{Co}^{2+}$ and $\mathrm{X}=2$ in case of $\left.\mathrm{Cu}^{2+}\right)$ in absolute EtOH. The general formulae of the two complexes derived by the chemical method are $\left[\mathrm{Cu}(\mathrm{L})_{2}(\mathrm{EtOH})_{2}\right] \mathrm{Cl}_{2}$ and $\left[\mathrm{Co}(\mathrm{L})_{2} \mathrm{Cl}_{2}\right] \mathrm{Cl}$. These complexes were used to synthesize another two complexes using tribochemical reaction by grinding the previous chloride complexes with excess $\mathrm{KI}$ in agate mortar in the solid state. The isolated complexes have the general formulae, $\left[\mathrm{Cu}(\mathrm{L}) \mathrm{I} \cdot \mathrm{H}_{2} \mathrm{O}\right] \cdot 1 / 2 \mathrm{H}_{2} \mathrm{O}$ and $\left[\mathrm{Co}(\mathrm{L}) \mathrm{I}_{3}(\mathrm{Et}-\right.$ $\mathrm{OH})] \cdot 3 \mathrm{EtOH}$. The results indicate the substitution of the chloride by iodide ions during grinding and extraction of the complexes by solvents. The IR spectra of the complexes suggest that $L$ acts in a bidentate manner towards the metal ions. Moreover, the results of electronic spectra and magnetic measurements for the chloride complexes suggest distorted-octahedral structure for $\mathrm{Cu}^{2+}$ and low-spin octahedral structures around the $\mathrm{Co}^{\mathrm{II}}$ and $\mathrm{Cu}^{2+}$ ions, respectively. On the other hand the data suggest that the iodide complexes have square-planer and low-spin for the $\mathrm{Cu}^{+}$and $\mathrm{Co}^{3+}$ ions, respectively. The results of mass spectra confirm the formulae proposed for the isolated complexes. The mechanisms of reduction of $\mathrm{Cu}^{\mathrm{II}}$ and oxidation of $\mathrm{Co}^{\mathrm{II}}$ for the metal complexes were elucidated.

\section{Keywords}

Tribochemical Reactions, Derivatives of Thiourea Complexes, $\mathrm{Cu}^{2+}$ and $\mathrm{Co}^{3+} \mathrm{Complexes}$ 


\section{Introduction}

Thiourea is the analogue compound to urea and has a considerably wide range of applications. The properties of urea and thiourea differ significantly because of the difference in electronegativity between sulfur and oxygen [1]. Thiourea derivatives are selective analytical reagents, especially for the determination of transition metal in complexes [2]. The biological activity of thiourea complexes has been successfully screened for various biological actions. On the other hand some thiourea derivatives have been used in commercial fungicides [3]-[6]. Substituted thioureas have recently gained much interest in the synthesis of wide variety of biologically active compounds [7] [8]. The complexing capacity of thiourea derivatives has been reported in several papers [9] [10]. The metal complexes of thiourea are neutral and their colors vary with the nature of the metal ions. These chelating agents have been remarkable ones for analytical chemistry [11]. Also, thiourea coordinates to metal ions as neutral ligands, monoanions and dianions [12] [13]. Our goal in this paper is to prepare novel metal complexes via chemical and tribochemical methods. The isolated complexes were characterized by chemical and spectral measurements. Finally a comparative study has been described and discussed.

\section{Experimental}

$N$-(O-hydoxyphenyl)- $N$ '-phenylthiourea (L) was synthesized by refluxing equivalent amounts of 2-aminophenol (10.9 g) dissolved in EtOH and phenyl isothiocyanate $(12 \mathrm{ml})$ on hot plate for $2 \mathrm{~h}$. The white product (m.p.; $138^{\circ} \mathrm{C}$; yield: $\left.93 \%\right)$ was obtained by cooling and characterized by chemical and spectral methods. The ligand (L) is insoluble in most organic solvents but easily soluble in DMF and DMSO.

\subsection{Preparation of Metal Complexes}

Preparation of $\mathrm{Cu}^{2+}$ and $\mathrm{Co}^{2+}$ Complexes by Chemical Method

Two complexes derived from $\mathrm{Cu}^{2+}$ and $\mathrm{Co}^{2+}$ ions with the general formulae, $\left[\mathrm{Cu}(\mathbf{L})_{2}\left(\mathrm{EtOH}_{2}\right)\right] \mathrm{Cl}_{2}$ and $\left[\mathrm{Co}(\mathbf{L})_{2}-\right.$ $\mathrm{Cl}_{2} \mathrm{CCl}$, were synthesized by the direct reaction of $\mathrm{CuCl}_{2} \cdot 2 \mathrm{H}_{2} \mathrm{O}(1.7 \mathrm{~g}, 0.01 \mathrm{~mol})$ and/or $\mathrm{CoCl}_{2} \cdot 6 \mathrm{H}_{2} \mathrm{O}(2.8 \mathrm{~g}, 0.01$ $\mathrm{mol})$ dissolved in EtOH $(50 \mathrm{ml})$ with $N$-(O-hydoxyphenyl)- $N$ '-phenylthiourea $(4.8 \mathrm{~g}, 0.01 \mathrm{~mol})$ dissolved in absolute EtOH $(25 \mathrm{ml})$. The reaction mixtures were refluxed on a water bath for $\sim 3 \mathrm{~h}$. The two complexes were filtered off, washed several times with absolute EtOH followed by dry diethyl ether and finally dried in a vacuum desiccator over anhydrous $\mathrm{CaCl}_{2}$. The results of elemental analyses and some physical properties are shown in Table 1.

\subsection{Physical Measurements}

The contents of copper and cobalt were carried using complexometric titration and xylenol orange as an indicator [14]. Elemental analyses contents (C, H and N) were determined at the Microanalytical Unit, Center of King Fahad Institute at Jeddah, Saudi Arabia. Molar conductivities measurements were carried out using Tacussel model CD 75. The chloride contents were determined as AgCl [14]. The IR spectra in the $200-4000 \mathrm{~cm}^{-1} \mathrm{range}^{-}$ were recorded in $\mathrm{KBr}$ on a Mattson 5000 FTIR Spectrometer. The electronic spectra of the $\mathrm{Cu}^{+}, \mathrm{Cu}^{2+}, \mathrm{Co}^{2+}$ and $\mathrm{Co}^{3+}$ complexes were recorded in Nujol mull in the range $(200-900 \mathrm{~nm})$ using Unicam spectrometer model

Table 1. Physical and chemical analysis of $\mathrm{L}$ and its complexes.

\begin{tabular}{|c|c|c|c|c|c|c|c|c|c|}
\hline \multirow{2}{*}{$\begin{array}{l}\text { Compound; } \\
\text { Empirical formula }\end{array}$} & \multirow{2}{*}{ (F. Wt) } & \multirow{2}{*}{ Color } & \multirow{2}{*}{$\begin{array}{l}\text { M.p. } \\
\left({ }^{\circ} \mathrm{C}\right)\end{array}$} & \multicolumn{4}{|c|}{ \% Found (Calcd.) } & \multirow{2}{*}{$\begin{array}{c}\mathbf{A}_{\mathrm{m}}^{+} \\
\text {(DMSO) }\end{array}$} & \multirow{2}{*}{$\begin{array}{c}\text { Yield } \\
(\%)\end{array}$} \\
\hline & & & & C & $\mathbf{H}$ & $\mathbf{N}$ & $\mathrm{S}$ & & \\
\hline $\mathbf{L} ; \mathrm{C}_{13} \mathrm{H}_{12} \mathrm{~N}_{2} \mathrm{OS}$ & 244.321 & White & $137-139$ & $63.7(63.9)$ & $5.0(5.0)$ & $11.3(11.5)$ & $13(13.1)$ & - & 94 \\
\hline $\begin{array}{c}\left.[\mathrm{Cu}(\mathbf{L}) \mathrm{EtOH})_{2}\right] \mathrm{Cl}_{2} \\
\mathrm{C}_{30} \mathrm{H}_{36} \mathrm{CuN}_{4} \mathrm{O}_{2} \mathrm{Cl}_{3}\end{array}$ & 715.228 & Yellowish-green & 171 & $50.4(50.4)$ & $4.2(5.1)$ & $7.2(7.8)$ & $9.6(9.9)$ & 66.3 & 83 \\
\hline $\begin{array}{c}{\left[\mathrm{Co}(\mathbf{L})_{2} \mathrm{Cl}_{2}\right] \mathrm{Cl}} \\
\mathrm{C}_{26} \mathrm{H}_{24} \mathrm{CoN}_{4} \mathrm{O}_{2} \mathrm{Cl}_{3}\end{array}$ & 653.931 & Brown & 146 & $47.8(47.8)$ & $3.6(3.7)$ & $9.2(8.6)$ & $8.8(9.8)$ & 49 & 80 \\
\hline $\begin{array}{c}{\left[\mathrm{Cu}(\mathbf{L}) \mathrm{I} . \mathrm{H}_{2} \mathrm{O}\right] \cdot 1 / 2 \mathrm{H}_{2} \mathrm{O}} \\
\quad \mathrm{C}_{13} \mathrm{H}_{15} \mathrm{CuN}_{2} \mathrm{O}_{2.5} \mathrm{I}\end{array}$ & 461.795 & Pale yellow & 260 & 33.3 (33.8) & $2.9(3.3)$ & $6.8(6.1)$ & $6.2(6.9)$ & 10.2 & 74 \\
\hline $\begin{array}{l}{\left[\mathrm{Co}(\mathbf{L}) \mathrm{I}_{3} \mathrm{EtOH}\right] \cdot 3 \mathrm{EtOH} ;} \\
\quad \mathrm{C}_{221} \mathrm{H}_{36} \mathrm{CoN}_{2} \mathrm{O}_{5} \mathrm{I}_{3}\end{array}$ & 868.261 & Yellowish-brown & 154 & $28.1(29.1)$ & $4.3(4.2)$ & $3.4(3.2)$ & $3.6(3.8)$ & 6.7 & 71 \\
\hline
\end{tabular}


UV2. ${ }^{1} \mathrm{H}-\mathrm{NMR}$ spectra of the free ligand and some of its metal complexes $\left(\mathrm{Cu}^{+}\right.$and $\left.\mathrm{Co}^{3+}\right)$ were recorded on Jeol-90Q Fourier transform (200 MHz) in $\mathrm{CDCl}_{3}$ and ${ }^{1} \mathrm{H}-\mathrm{NMR}$ Spectrometer $\left(400 \mathrm{MHz}\right.$ ) in $\mathrm{d}_{6}$-DMSO at King Saud University at Riyadh, Saudi Arabia. Magnetic moments were determined using a Sherwood balance at room temperature $\left(25^{\circ} \mathrm{C}\right)$ with $\mathrm{Hg}\left[\mathrm{Co}(\mathrm{NSC})_{4}\right]$ as a calibrate. The diamagnetic corrections for the ligand and the metal atoms were computed using Pascal's constants [15].

\section{Results and Discussion}

The results of the isolated solid complexes are listed in Table 1. All the isolated metal complexes are colored, stable against light and insoluble in most common organic solvents but easily soluble in DMF and DMSO. The molar conductivities for the chloride complexes, $\left.[\mathrm{Cu}(\mathbf{L}) \mathrm{EtOH})_{2}\right] \mathrm{Cl}_{2}$ and $\left[\mathrm{Co}(\mathbf{L})_{2} \mathrm{Cl}_{2}\right] \mathrm{Cl}$, in DMSO at $25^{\circ} \mathrm{C}$ are 66.3 and $49.0 \Omega^{-1} \cdot \mathrm{cm}^{2} \cdot \mathrm{mol}^{-1}$ indicating $1: 2$ and $1: 1$ electrolyte, respectively. The electrolytic nature of these complexes [16], except the two iodide complexes of the general formulae, $\left[\mathrm{Cu}(\mathrm{L}) \mathrm{I} \cdot \mathrm{H}_{2} \mathrm{O}\right] \cdot 1 / 2 \mathrm{H}_{2} \mathrm{O}$ and $[\mathrm{Co}(\mathbf{L})$ $\left.\mathrm{I}_{3} \cdot \mathrm{EtOH}\right] \cdot 3 \mathrm{EtOH}$ are non-conducting in DMSO. Also, the results show that the metal complexes have comparatively low melting points $\left(146^{\circ} \mathrm{C}-260^{\circ} \mathrm{C}\right)$ suggesting a weak bonding between the metal ions and $\mathbf{L}$. The structure of the ligand $(\mathbf{L})$ is shown in Figure 1.

The IR spectrum of $\mathbf{L}$ in $\mathrm{KBr}$ (Figure 2) shows several bands at 3530, 3220, 3156 and $2948 \mathrm{~cm}^{-1}$ assigned to $v(\mathrm{OH}$; free), $v(\mathrm{NH}$; free), $v(\mathrm{NH}$; hydrogen-bonded) and $v(\mathrm{OH}$; hydrogen-bonded) vibrations, respectively. The bands observed at 1594, 1267 and $765 \mathrm{~cm}^{-1}$ are assigned to $v(\mathrm{C}=\mathrm{C})$ vibration while the latter two bands are assigned to $v$ (CS) vibrations, respectively. The observation of broad weak bands in the $1940-1700$ and 2750 $2500 \mathrm{~cm}^{-1}$ region suggests the presence of intra-molecular hydrogen bonding of the types O-H...N and/or $\mathrm{N}-\mathrm{H} . . . \mathrm{O}$ [17] [18]. The results suggest that the first type of the hydrogen bonding $(\mathrm{O}-\mathrm{H} . . . \mathrm{N})$ is more likely occurred.

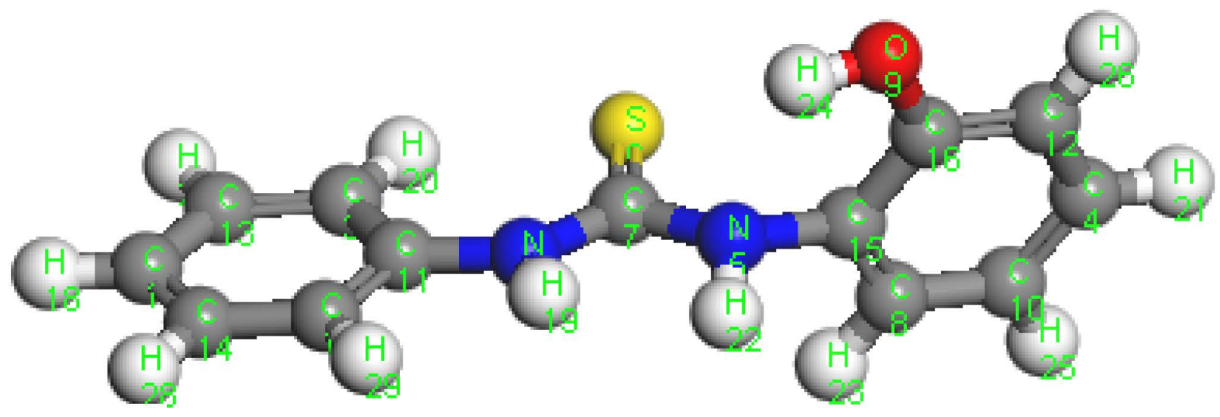

Figure 1. Structure of the ligand (L).

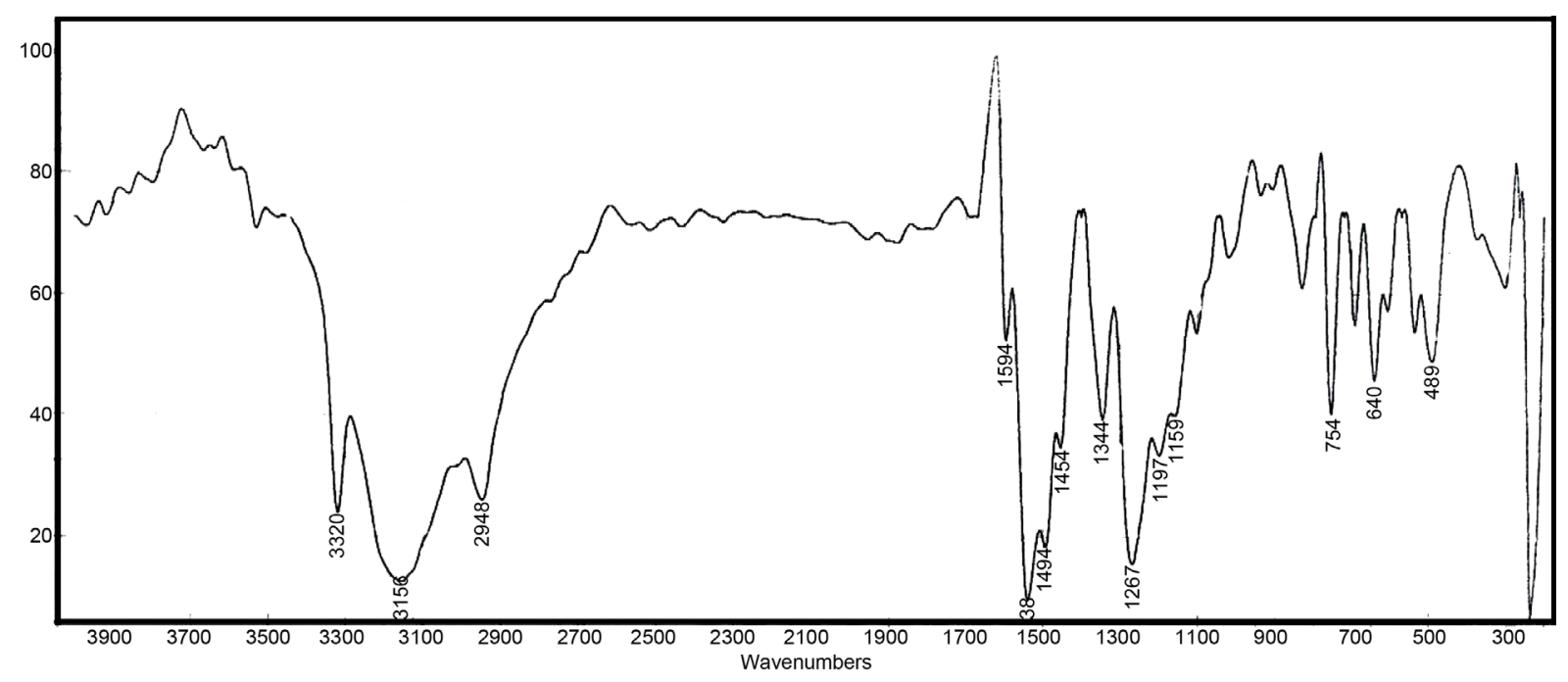

Figure 2. IR spectrum of $\mathbf{L}$ in $\mathrm{KBr}$. 
The ${ }^{1} \mathrm{H}$-NMR spectrum of $\mathbf{L}$ in $\mathrm{d}_{6}$-DMSO (Figure 3) displays four signals with equal intensities at 9.98, 9.82, 9.12 and 8.1, relative to TMS. The first two signals are assigned to the $\mathrm{OH}$ (hydrogen-bonded) and $\mathrm{OH}$ (free) protons, respectively. The results are taken as strong evidence for the existence of hydrogen bonding and confirm the results from IR spectrum. The latter two signals are attributed to the protons of NH attached to (NH-CS) and $(\mathrm{NH}-\mathrm{Ph})$, respectively. The multiplet signals in the $(7.57$ - 6.79) ppm region are assigned to the protons of the two phenyl rings attached to the thiourea moiety.

A comparison of the IR spectra of $\mathbf{L}$ with $\mathrm{Cu}^{2+}$ and $\mathrm{Co}^{2+}$ complexes allows us to determine the mode of bonding. The IR spectra of the two complexes obtained by chemical method with the general formulae, $[\mathrm{Cu}(\mathbf{L})-$ $\left.\mathrm{EtOH})_{2}\right] \mathrm{Cl}_{2}$ (Figure 4) and $\left[\mathrm{Co}(\mathbf{L})_{2} \mathrm{Cl}_{2}\right] \mathrm{Cl}$ (Figure 5), indicate that the $\mathbf{L}$ behaves in a bidentate manner and coordinates via the $\mathrm{OH}$ and $\mathrm{NH}$ groups forming five-member ring around the metal ions (Figure 6 and Figure 7). The negative shifts of these two bands to lower wave numbers show the involvement of both the $\mathrm{OH}$ and $\mathrm{NH}$ groups in bonding. In comparing the IR data of $\mathbf{L}$ with the complexes we observed that the CS group remains more or less at the same position excluding the participation of this group in bonding.

The electronic spectra of the complexes of the $\mathrm{Cu}^{2+}$ and $\mathrm{Co}^{3+}$ with the general formulae, $\left[\mathrm{Cu}(\mathbf{L})(\mathrm{EtOH})_{2}\right] \mathrm{Cl}_{2}$ (Figure 8) and $\left[\mathrm{Co}(\mathbf{L})_{2} \mathrm{Cl}_{2}\right] \mathrm{Cl}$ (Figure 9), were carried out in Nujol mull. The spectra of the first $\mathrm{Cu}^{2+}$ complex show a band at $14,368 \mathrm{~cm}^{-1}$ for the former $\mathrm{Cu}^{2+}$ complex which is attributed to ${ }^{2} \mathrm{E}_{\mathrm{g}} \rightarrow{ }^{2} \mathrm{~T}_{2 \mathrm{~g}}$ transition [19] in an distorted-octahedral geometry around the $\mathrm{Cu}^{2+}$ ion. The value of magnetic moment is 1.8 B.M. is taken as additional evidence for the existence of distorted-octahedral geometry around the $\mathrm{Cu}^{2+}$ ion. On the other hand, the diamagnetic nature of the $\mathrm{Co}^{2+}$ complex suggests the oxidation of $\mathrm{Co}^{2+}$ to $\mathrm{Co}^{3+}$ and the complex has a $\mathrm{d}^{6}$-configuration (low-spin). The electronic spectrum of $\left[\mathrm{Co}(\mathbf{L})_{2} \mathrm{Cl}_{2}\right] \mathrm{Cl}$ in Nujol mull shows three bands in the 15,700,

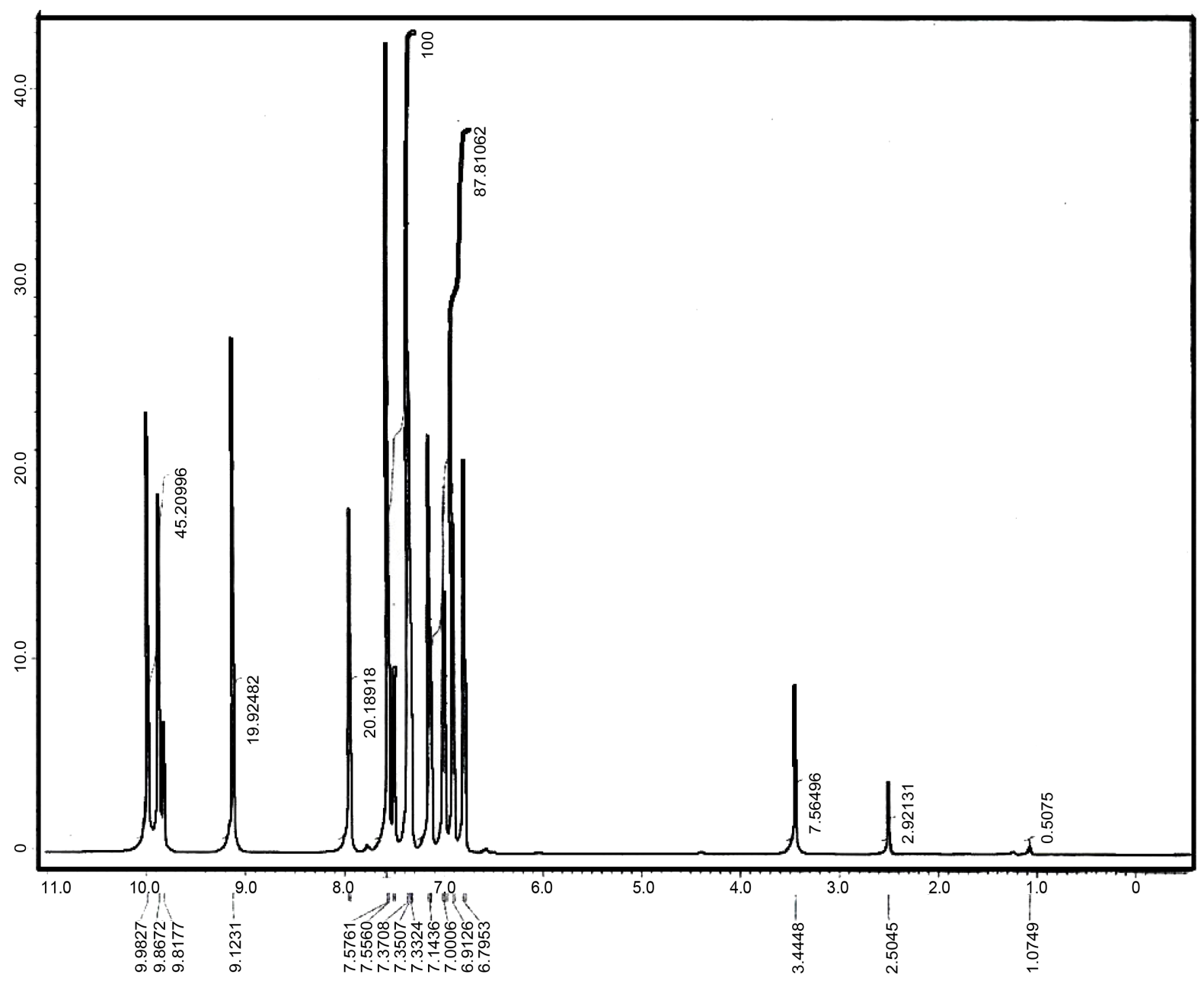

Figure 3. ${ }^{1} \mathrm{H}-\mathrm{NMR}$ spectrum of $\mathbf{L}$ in $\mathrm{d}_{6}$-DMSO. 


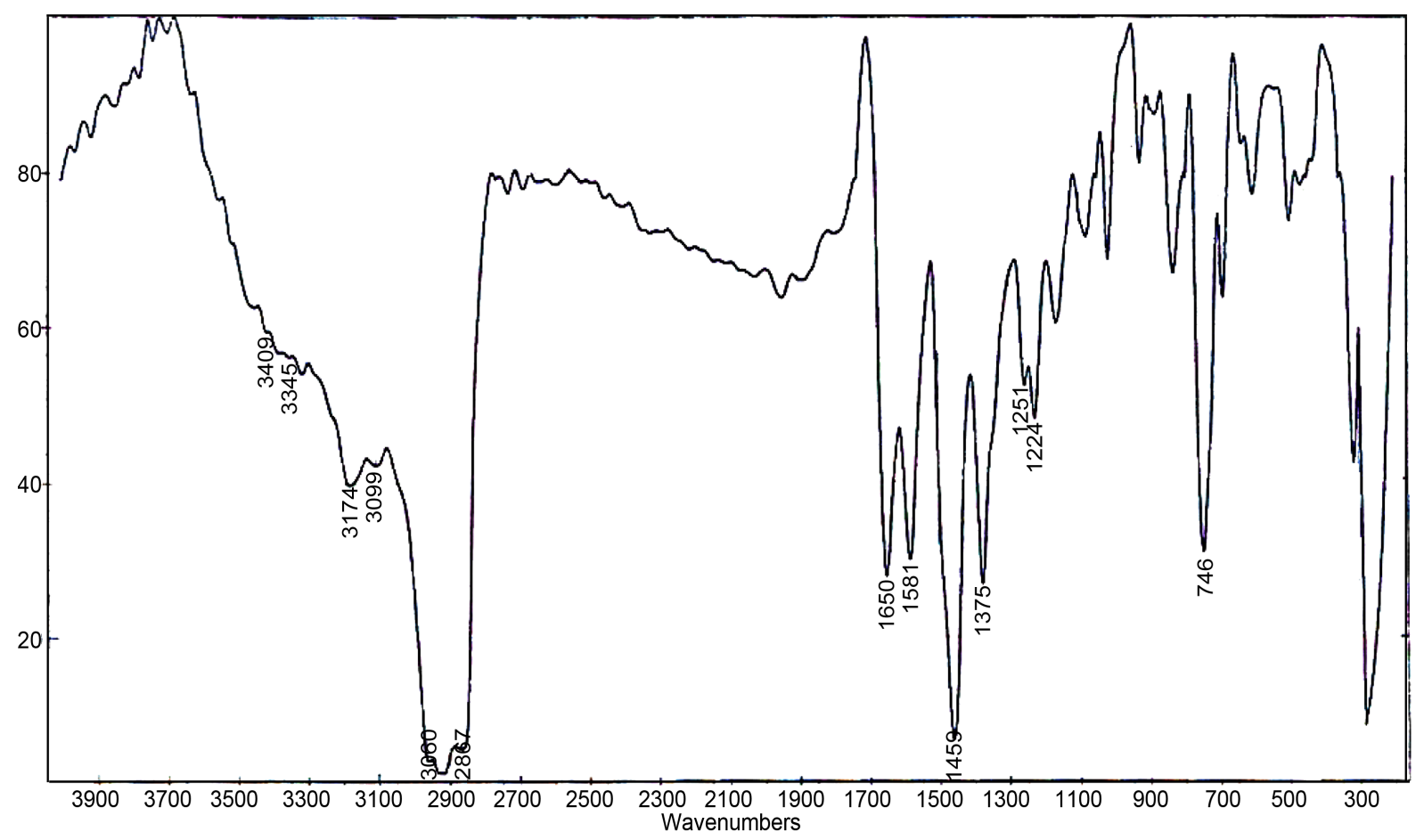

Figure 4. IR spectrum of $\left.[\mathrm{Cu}(\mathbf{L}) \mathrm{EtOH})_{2}\right] \mathrm{Cl}_{2}$ in nujol mull.

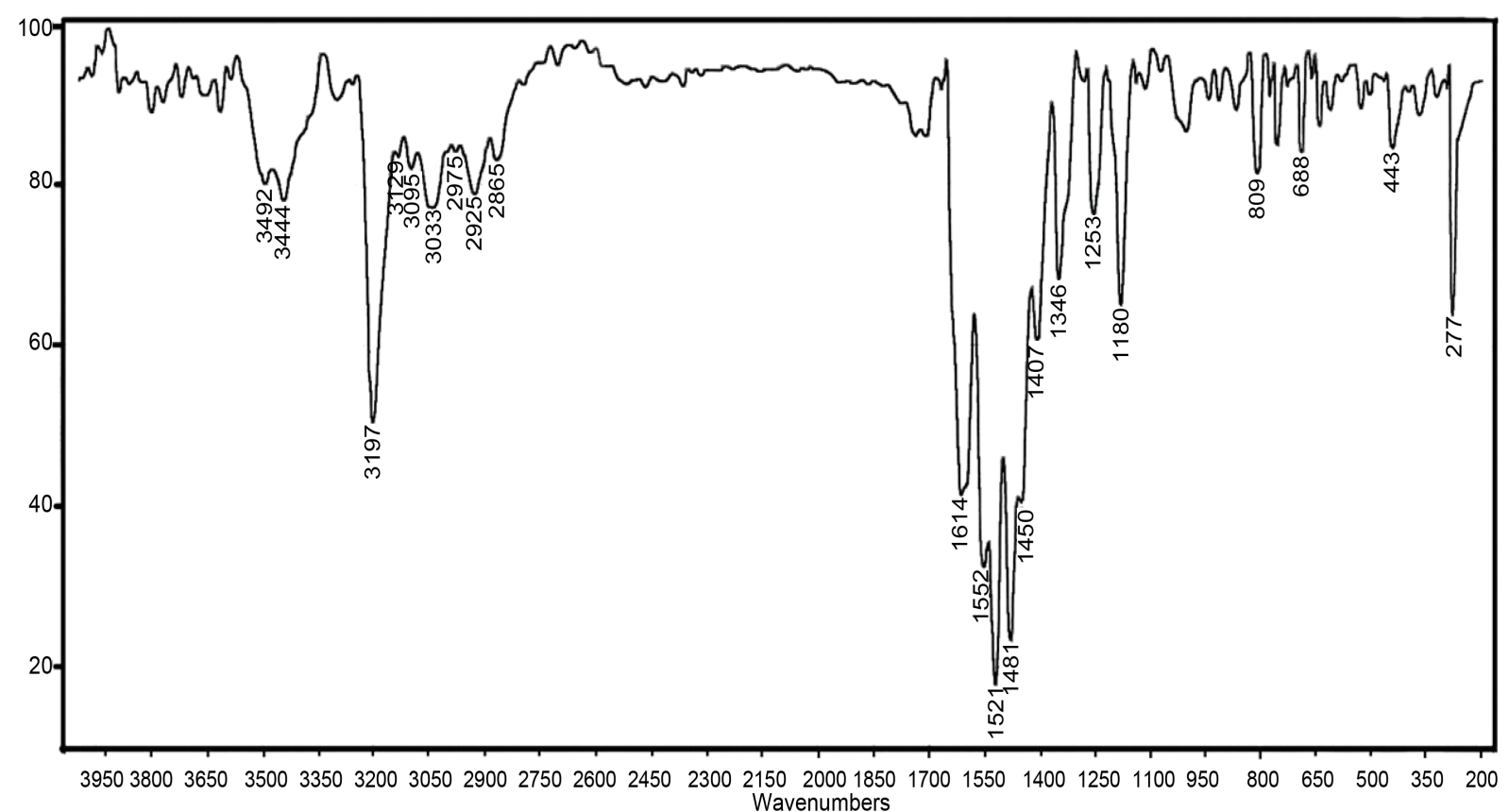

Figure 5. IR spectrum of $\left[\mathrm{Co}(\mathbf{L})_{2} \mathrm{Cl}_{2}\right] \mathrm{Cl}$ in nujol mull.

19,840 and 21,740 - 28,900 $\mathrm{cm}^{-1}$ regions attributed to the ${ }^{1} \mathrm{~A}_{1 \mathrm{~g}} \rightarrow{ }^{3} \mathrm{~T}_{2 \mathrm{~g}},{ }^{1} \mathrm{~A}_{1 \mathrm{~g}} \rightarrow{ }^{1} \mathrm{~T}_{1 \mathrm{~g}}$ and ${ }^{1} \mathrm{~A}_{1 \mathrm{~g}} \rightarrow{ }^{1} \mathrm{~T}_{2 \mathrm{~g}}$ transitions, respectively, in a low-spin $\mathrm{Co}^{3+}$ system. The observation of these three bands may also suggest that the complexes have trans-configuration [20] [21].

The $\mathrm{Cu}^{+}$and $\mathrm{Co}^{3+}$ complexes synthesized by tribochemical reaction are diamagnetic in nature. Also, the absent of any d-d transition bands in case of the $\mathrm{Cu}^{+}$complex synthesized is taken as evidence for the reduction of $\mathrm{Cu}^{2+}$ to $\mathrm{Cu}^{+}$. Figure 10 illustrates the structure of the iodide complex $\left[\mathrm{Cu}(\mathbf{L}) \mathrm{I} \cdot \mathrm{H}_{2} \mathrm{O}\right] \cdot 1 / 2 \mathrm{H}_{2} \mathrm{O}$. The mechanism of 

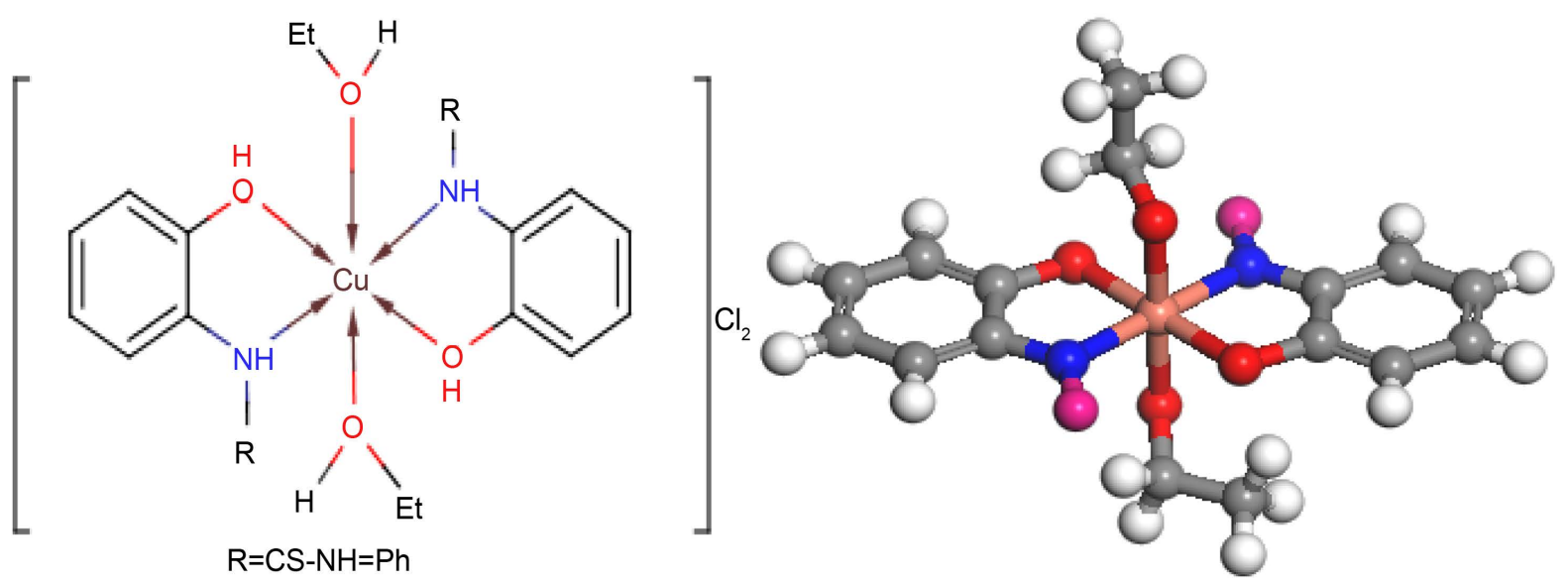

Figure 6. Structure of $\left[\mathrm{Cu}(\mathbf{L})(\mathrm{EtOH})_{2}\right] \mathrm{Cl}_{2}$.
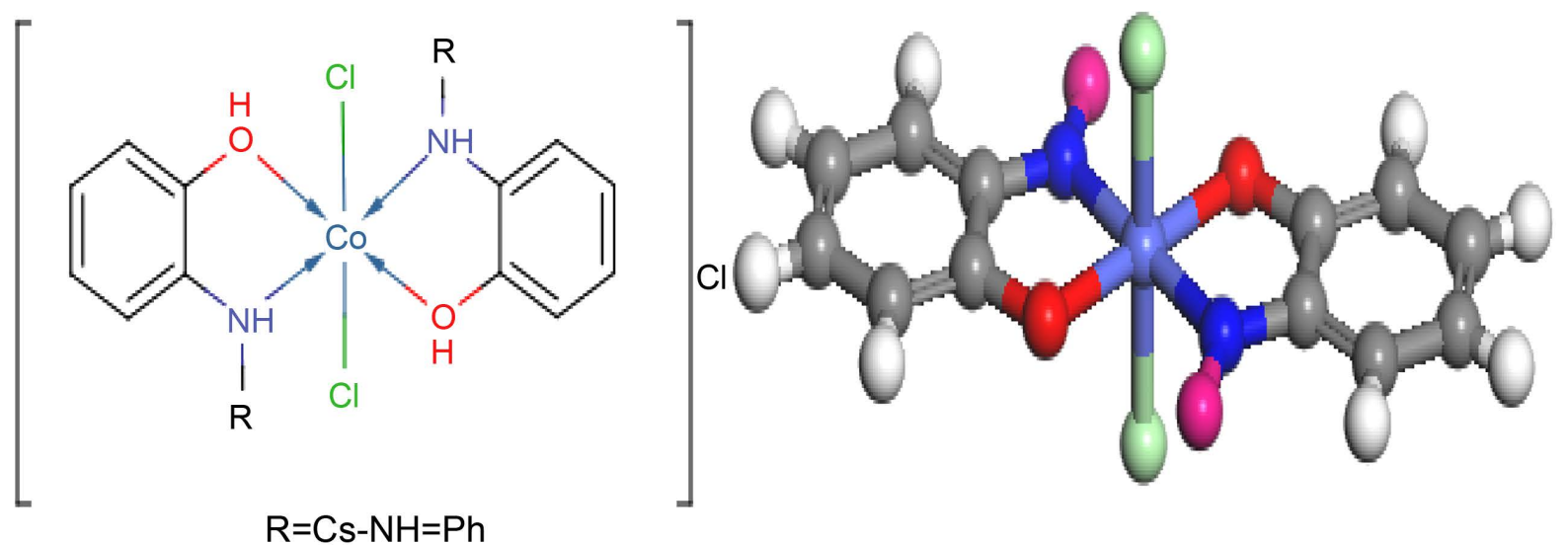

Figure 7. Structure of $\left[\mathrm{Co}(\mathbf{L})_{2} \mathrm{Cl}_{2}\right] \mathrm{Cl}$.

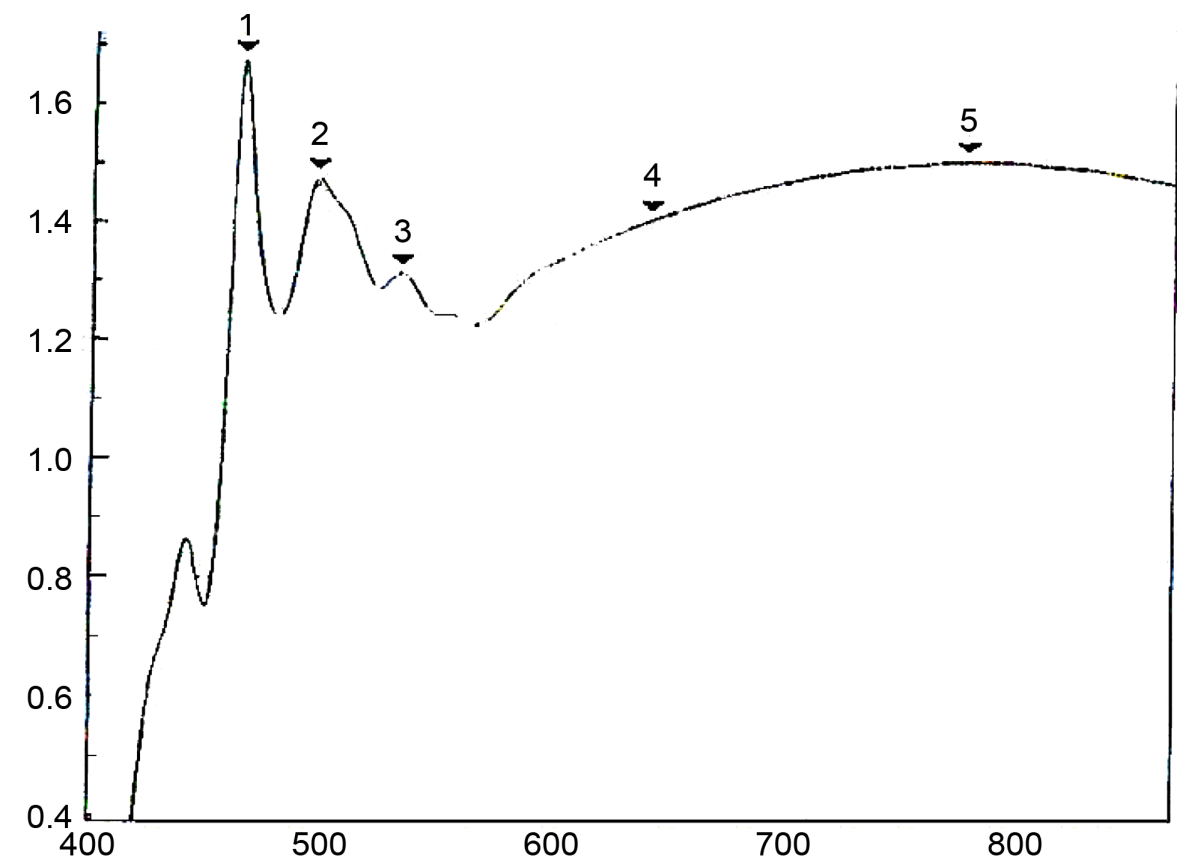

Figure 8. The electronic spectrum of $\left[\mathrm{Cu}(\mathbf{L})(\mathrm{EtOH})_{2}\right] \mathrm{Cl}_{2}$ in nujol mull. 


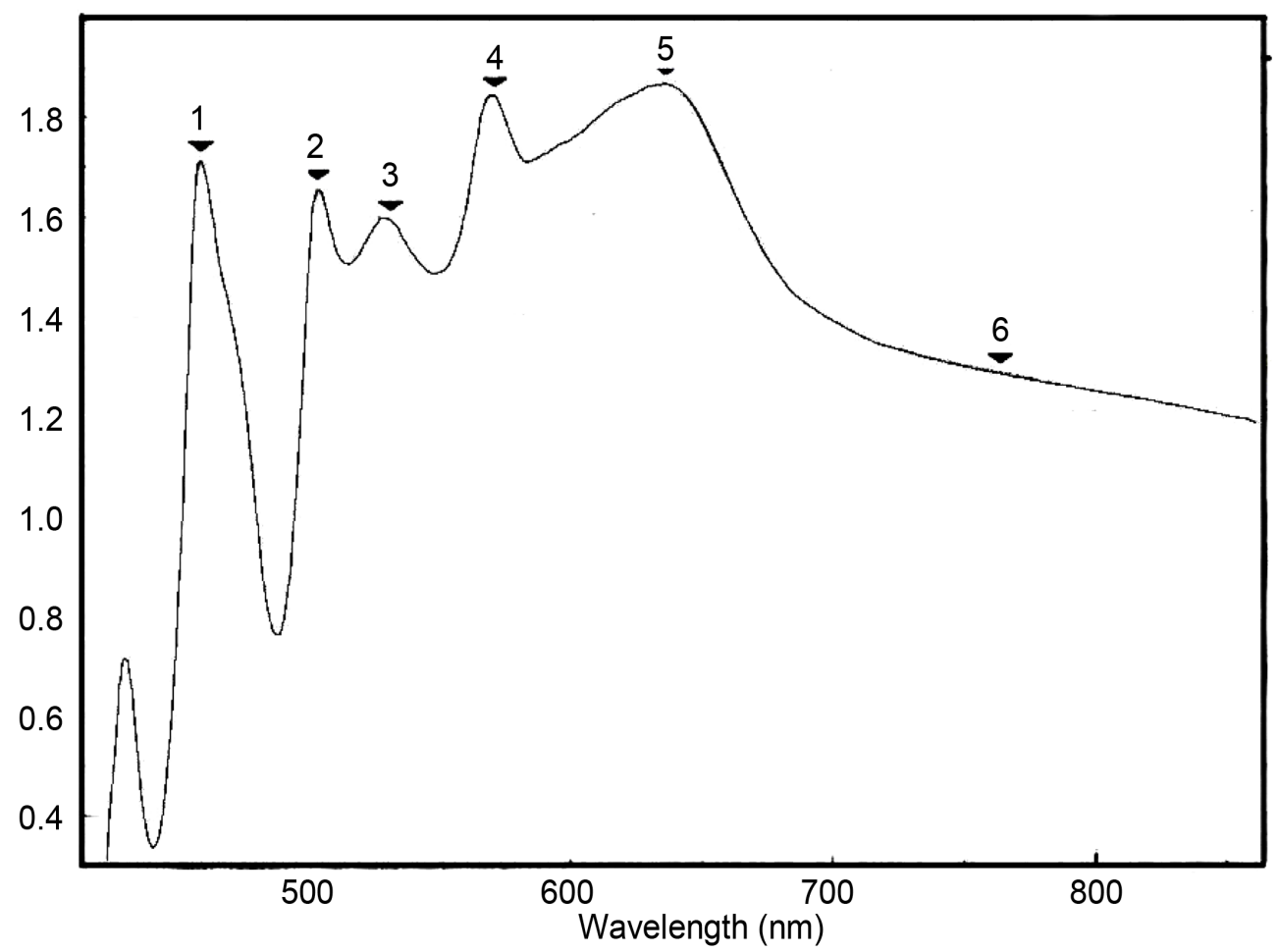

Figure 9. The electronic spectrum of $\left[\mathrm{Co}(\mathbf{L})_{2} \mathrm{Cl}_{2}\right] \mathrm{Cl}$ in nujol mull.

\lceil<smiles>[R]N1c2ccccc2O[C@]1(I)OO</smiles>

$1 / 2 \mathrm{H}_{2} \mathrm{O}$

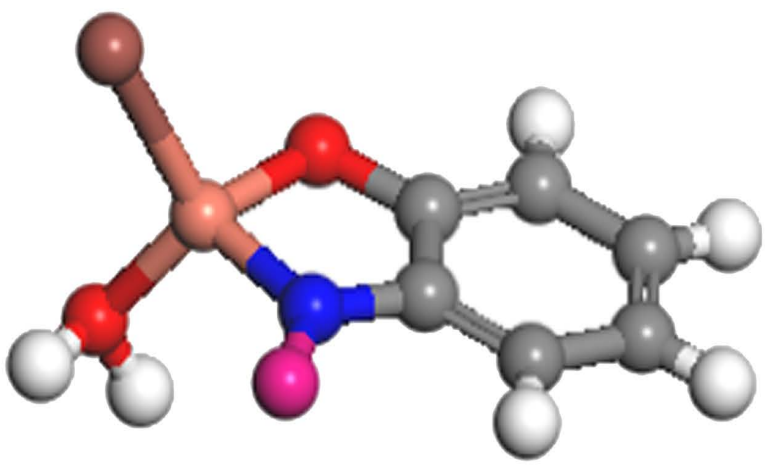

\section{$\mathrm{R}=\mathrm{Cs}-\mathrm{NH}=\mathrm{Ph}$}

Figure 10. Structure of $\left[\mathrm{Cu}(\mathbf{L})\left[\cdot \mathrm{H}_{2} \mathrm{O}\right] \cdot 1 / 2 \mathrm{H}_{2} \mathrm{O}\right.$.

reduction of $\mathrm{Cu}^{2+}$ to $\mathrm{Cu}^{+}$as well as the substitution of chloride by iodide ions during grinding and extraction by solvent is reported in our earlier work [22].

The IR spectrum of the $\mathrm{Co}^{3+}$ complex with the general formula, $\left[\mathrm{Co}(\mathbf{L}) \mathrm{I}_{3}(\mathrm{EtOH})\right] \cdot 3 \mathrm{EtOH}$ (Figure 11), shows that the ligand behaves in a bidentate manner via the $\mathrm{OH}$ of the phenolic group and $\mathrm{NH}$ groups as discussed above. Also, the mechanism of oxidation of $\mathrm{Co}^{2+}$ to $\mathrm{Co}^{3+}$ as well as the substitution of chloride by iodide ions during grinding and extraction by solvent is reported earlier by Mostafa et al. [22]. The reduction process is observed in case of the reduction of $\mathrm{Cu}^{2+}$ to $\mathrm{Cu}^{+}$while the oxidation process in case of $\mathrm{Co}^{2+}$ to $\mathrm{Co}^{3+}$ complexes. Both types are diamagnetic in nature, which explains the nature of the isolated complexes.

The ${ }^{1} \mathrm{H}-\mathrm{NMR}$ spectra of the $\mathrm{Cu}^{+}$and $\mathrm{Co}^{3+}$ complexes in $\mathrm{d}_{6}$-DMSO (Figure 12 and Figure 13) with the general formulae, $\left[\mathrm{Cu}(\mathbf{L}) \mathrm{I} \cdot \mathrm{H}_{2} \mathrm{O}\right] \cdot 1 / 2 \mathrm{H}_{2} \mathrm{O}$ and $\left[\mathrm{Co}(\mathbf{L}) \mathrm{I}_{3}(\mathrm{EtOH})\right] \cdot 3 \mathrm{EtOH}$, are more less the same except that the former shows the signals of the $\mathrm{OH}$ proton due to the water molecule at $6.5 \mathrm{ppm}$. The latter complex exhibits signals at 13.7, 4.1 and 3.2 ppm assigned to the protons of $\mathrm{OH}, \mathrm{CH}_{2}$ and $\mathrm{CH}_{3}$ of EtOH molecule, respectively. 

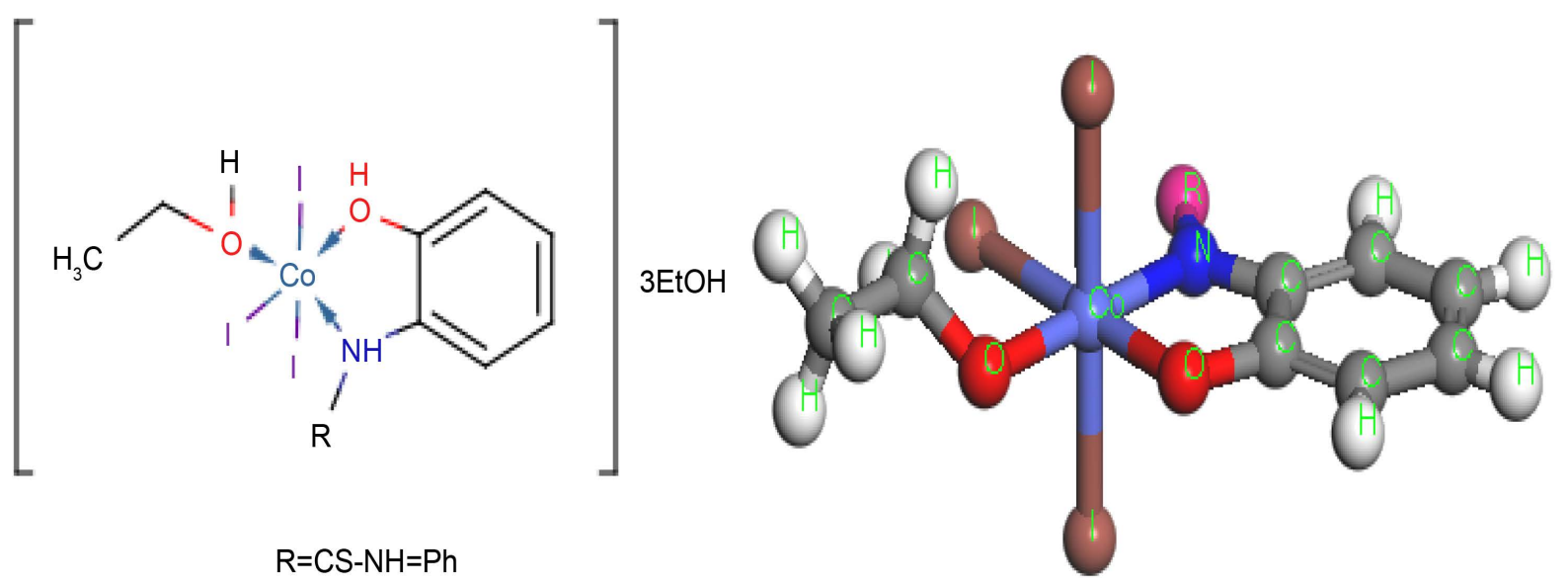

Figure 11. Structure of $\left[\mathrm{Co}(\mathbf{L}) \mathrm{I}_{3}(\mathrm{EtOH})\right] \cdot 3 \mathrm{EtOH}$.

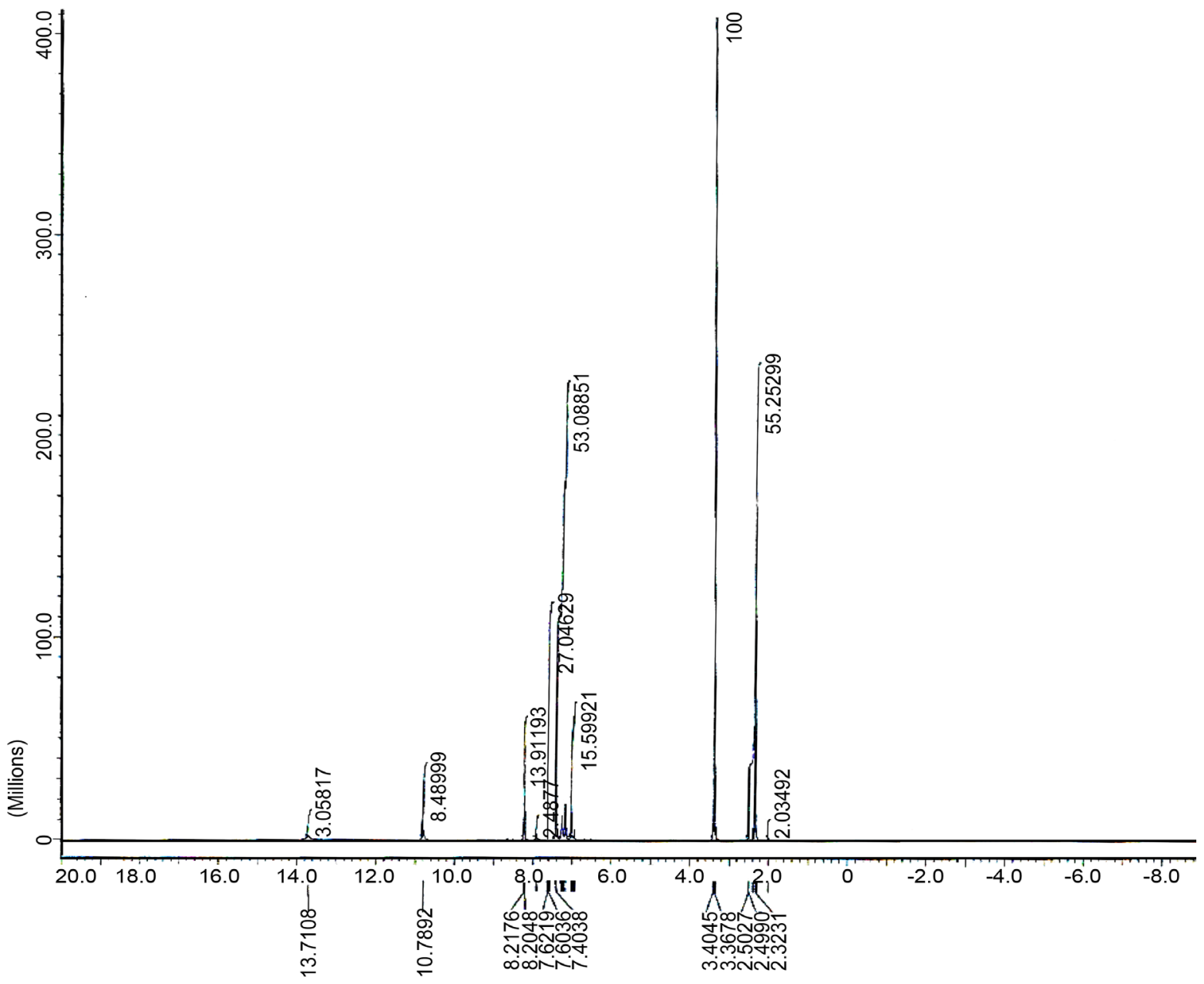

Figure 12. ${ }^{1} \mathrm{H}-\mathrm{NMR}$ spectrum of $\left[\mathrm{Co}(\mathbf{L}) \mathrm{I}_{3}(\mathrm{EtOH})\right] \cdot 3 \mathrm{EtOH}$ in $\mathrm{d}_{6}-\mathrm{DMSO}$.

\section{Conclusion}

In continuation of our earlier work on tribochemical reactions and the role of metal ions as well as the ligand used in reduction of $\mathrm{Cu}^{2+}$ and oxidation of $\mathrm{Co}^{2+}$, we extend our work to include $N$ - $\left(O\right.$-hydoxyphenyl)- $N N^{\prime}$-phenylthiourea $(\mathbf{L})$ with $\mathrm{Cu}^{+}, \mathrm{Cu}^{2+}, \mathrm{Co}^{2+}$ and $\mathrm{Co}^{3+}$ by chemical and tribochemical reactions. The ligand coordinates 


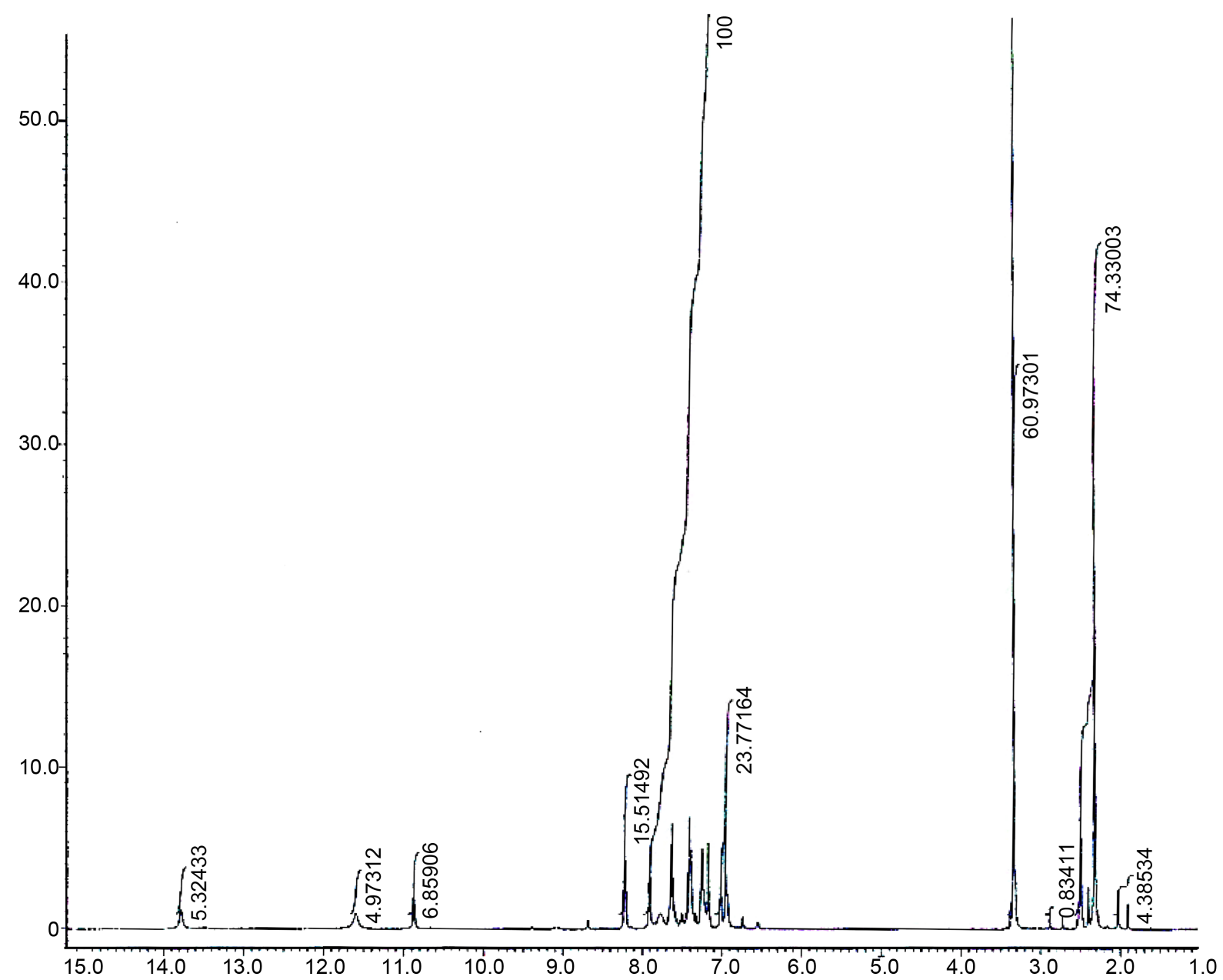

Figure 13. ${ }^{1} \mathrm{H}-\mathrm{NMR}$ spectrum of $\left[\mathrm{Co}(\mathbf{L}) \mathrm{I}_{3}(\mathrm{EtOH})\right] \cdot 3 \mathrm{EtOH}$ in $\mathrm{d}_{6}-\mathrm{DMSO}$.

in a bidentate manner towards the metal ions. The results indicate that the substitution of the chloride by iodide ions has occurred in $\mathrm{Cu}^{2+}$ and $\mathrm{Co}^{2+}$ complexes. Also, the reduction of $\mathrm{Cu}^{2+}$ to $\mathrm{Cu}^{+}$and the oxidation of $\mathrm{Co}^{2+}$ to $\mathrm{Co}^{3+}$ have occurred and been confirmed by chemical, spectral and magnetic measurements.

\section{References}

[1] Alkan, G., Tek, Y. and Kahraman D. (2011) Preparation and Characterization of a Series of Thiourea Derivatives as Phase Change Materials for Thermal Energy Storage. Turkish Journal of Chemistry, 35, 769-777.

[2] Schuster, M. (1992) Selective Complexing Agents for the Trace Enrichment of Platinum Metals. Journal of Analytical Chemistry, 342, 791-794. http://dx.doi.org/10.1007/BF00322135

[3] French, F.A. and Blanz, E.J. (1965) The Carcinostatic Activity of x-(N)-Heterocyclic Carboxaldehyde Thiosemicarbazones. I. Isoquinoline-1-Carboxaldehyde Thiosemicarbazone. Cancer Research, 25, 1454-1458.

[4] Blanz, E.J. and French, F.A. (1968) The Carcinostatic Activity of 5-Hydroxy-2-Formyl Pyridine Thiosemicarbazone. Cancer Research, 28, 2419-2422.

[5] French, F.A. and Blanz, E.J. (1966) The Carcinostatic Activity of Thiosemicarbazones of Formyl Heteroaromatic Compounds.1 III. Primary Correlation. Journal of Medicinal Chemistry, 9, 585-589. http://dx.doi.org/10.1021/jm00322a032

[6] French, F.A., Blanz, E.J., Doamaral, J.R. and French, D.A. (1970) Carcinostatic Activity of Thiosemicarbazones of Formyl Heteroaromatic Compounds. VI. 1-Formylisoquinoline Derivatives Bearing Additional Ring Substituents, with Notes on Mechanism of Action. Journal of Medicinal Chemistry, 13, 1117-1124. http://dx.doi.org/10.1021/jm00300a024 
[7] Ren, J., Diprose, J., Warren, J., Esnouf, R.M., Bird, L.E., Ikemizu, S., Slater, Milton, M., Balzarini, J., Stuart, D.I. and Stammers, D.K. (2000) Phenylethylthiazolylthiourea (PETT) Non-Nucleoside Inhibitors of HIV-1 and HIV-2 Reverse Transcriptases: Structural and Biochemical Analysis. Journal of Biological Chemistry, 275, 5633-5639. http://dx.doi.org/10.1074/jbc.275.8.5633

[8] Elmali, F.T., Avciata, U. and Demirhan, N. (2011) Synthesis and Characterization of New Thiourea Derivatives Substituted 1,10-Phenanthroline and Crown Ether. Main Group Chemistry, 10, 17-23.

[9] Schuster, M., Kugler, B. and Konig, K.H. (1990) The Chromatography of Metal-Chelates. 19. Influence of the Acyl Substituents on the Chromatographic Properties of Acylthiourea Chelates. Journal of Analytical Chemistry, 338, 717720. http://dx.doi.org/10.1007/BF00323412

[10] Konig, K.H., Schuster, M., Schneeweis, G. and Steinbrech, B. (1984) On the Chromatography of Metal Chelates. 14. Thin-Layer-Chromatography of N,N-Dialkyl-N'-benzoylthiourea Chelates. Zeitschrift für Analytische Chemie, 319, $66-$ 69.

[11] Hassan, O.A., Otaiwi, A.M. and Abeer, A. (2008) Photodegradation Study of PVC by New Metal Complexes of Thiourea Derivatives. National Journal of Chemistry, 31, 501-503.

[12] Rathod, M.S. and Jadhao, S.Z. (2012) Synthesis and Structural Investigation of Nickel Metal-Ligand (Thiourea Derivative) Complexes. Journal of Chemical and Pharmaceutical Research, 4, 1629-1631.

[13] Henderson, W., Nicholson, B.K. and Rickard, C.E.F. (2001) Platinum(II) Complexes of Chelating and Monodentate Thiourea Monoanions Incorporating Chiral, Fluorescent or Chromophoric Groups. Inorganica Chimica Acta, 320, 101 109. http://dx.doi.org/10.1016/S0020-1693(01)00473-X

[14] Vogel, A.I. (1961) A Text Book of Quantitative Inorganic Chemistry. Longmans, London.

[15] Lewis, L. and Wilkins, R.G. (1960) Modern Coordination Chemistry. Interscience, New York.

[16] Geary, W.J. (1971) The Use of Conductivity Measurements in Organic Solvents for the Characterization of Coordination Compounds. Coordination Chemistry Reviews, 7, 81-122. http://dx.doi.org/10.1016/S0010-8545(00)80009-0

[17] Burger, K., Ruff, I. and Ruff, F. (1965) Some Theoretical and Practical Problems in the Use of Organic Reagents in Chemical Analysis-IV Infrared and Ultraviolet Spectrophotometric Study of the Dimethylglyoxime Complexes of the Transition Metals. Journal of Inorganic and Nuclear Chemistry, 27, 179-190. http://dx.doi.org/10.1016/0022-1902(65)80208-1

[18] Bullock, J.I.N. and Tajimir-Riahi, H.A. (1978) Schiff-Base Complexes of the Lanthanoids and Actinoids. Part 1. Lanthanoid(III) Halide Complexes with the Un-Ionised form of $N N^{\prime}$-Ethylene-Bis(Salicylideneimine) and Related Bases. Journal of the Chemical Society, Dalton Transactions, 1978, 36-39. http://dx.doi.org/10.1039/DT9780000036

[19] Lever, A.B.P. (1984) Inorganic Electronic Spectroscopy. Elsevier, Amsterdam.

[20] Chan, S.C. and Poon C.K. (1966) Preparation, Properties, and Lsomerisation of Aqu of Luoro-Bis(Ethylenediamine) Cobalt(III) Cations. Journal of the Chemical Society, 1966, 146-150. http://dx.doi.org/10.1039/j19660000146

[21] Fujinami, S., Shibata, M. and Yamatera H. (1978) Relative Intensities of the Ligand-Field Transition Bands in Tetragonal Chromium(III) and Cobalt(III) Complexes. Bulletin of the Chemical Society of Japan, 51, 1391-1396. http://dx.doi.org/10.1246/bcsj.51.1391

[22] Al-Ashqar, S.M. and Mostafa, M.M. (2008) Synthesis of Some Novel Co ${ }^{\mathrm{II}}$ and $\mathrm{Co}^{\mathrm{III}}$ Complexes by Tribochemical Reactions Using KI with Some Derivatives of Thiosemicarbazide Complexes Derived From Girard's T and P. Spectrochimica Acta Part A: Molecular and Biomolecular Spectroscopy, 71, 1321-1326.

http://dx.doi.org/10.1016/j.saa.2008.04.003 


\section{Submit or recommend next manuscript to SCIRP and we will provide best service for you:}

Accepting pre-submission inquiries through Email, Facebook, LinkedIn, Twitter, etc.

A wide selection of journals (inclusive of 9 subjects, more than 200 journals)

Providing 24-hour high-quality service

User-friendly online submission system

Fair and swift peer-review system

Efficient typesetting and proofreading procedure

Display of the result of downloads and visits, as well as the number of cited articles

Maximum dissemination of your research work

Submit your manuscript at: http://papersubmission.scirp.org/ 